\title{
Influence of dissolved oxygen content on oxidative stability of linked polymer solution
}

\author{
Dong Zhao-xia*, Lin Mei-qin, Xin Jian and Li Ming-yuan \\ Enhanced Oil Recovery Research Center, China University of Petroleum, Beijing 102249, China
}

\begin{abstract}
The influence of dissolved oxygen content on the oxidative stability of a linked polymer solution (LPS) was studied by micro-filtration, dynamic light scattering and viscosity measurements. The results showed that at the same temperature, the degree of the oxidative degradation of the LPS increased and the rapidity of the oxidative degradation was accelerated with the increase of the dissolved oxygen content. Consequently, the size of linked polymer coils (LPCs) of the LPS became small, and the plugging capability of the LPS decreased. At a fixed content of dissolved oxygen, with increasing degradation temperature, almost the same results were observed, namely, an increased degree of oxidative degradation, accelerated rapidity of the oxidative degradation and decreased plugging capacity, with decreased oxidative stability of LPS. At $90{ }^{\circ} \mathrm{C}$, in the presence of oxygen, LPS lost its plugging capability after having been degraded for a period of time. But at $40^{\circ} \mathrm{C}$, LPS with low dissolved oxygen content could be stable for a long time. The decreased plugging ability of LPS after oxidative degradation is mainly caused by the decreased size and number of the LPCs due to the breaking of hydrolyzed polyacrylamide (HPAM) molecule segments and the structural changing of HPAM molecules.
\end{abstract}

Key words: Linked polymer solution, HPAM, content of dissolved oxygen, degradation, stability

\section{Introduction}

Linked polymer solution (LPS) is defined as an aqueous solution of dispersed cross-linked polymer coils (LPCs). LPS system had been successfully applied to crude oil production as an in-depth profile control agent ( $\mathrm{Li}$ et al, 2002) due to its low viscosity (Sun et al, 2003), suitable flow properties (Li et al, 2007; Luo et al, 2005; Shi et al, 2008) and ability of plugging pore throats in reservoirs (Sun et al, 2005a and 2005b). So far, the plugging ability (Luo et al, 2006; Zhu et al, 2006), rheological property (Sun et al, 2004), and formation conditions (Lin et al, 2007) of LPS have been well studied. It was found that the stability of LPS played a very important role in profile control and flooding. Shear stability and thermal stability of LPS have been studied, and the results showed that the plugging ability of LPS decreased under some shear stress (Lin et al, 2008a), and the degradation of LPS would be accelerated at high temperature (Lin et al, 2008b). In this paper the effects of oxygen content dissolved in the system on plugging ability of LPS, size of LPCs, viscosity of HPAM solution, and on size of HPAM coils are reported.

\section{Experimental}

\subsection{Materials and methods}

The polymer used in experiments is hydrolyzed

*Corresponding author. email: dzx@cup.edu.cn

Received March 20, 2009 polyacrylamide (HPAM) produced by Pfizer company (USA), with a viscosity average relative molecular mass $\left(M_{\eta}\right)$ of $1.80 \times 10^{7}$ and hydrolysis degree of $25.8 \%$. The cross-linker aluminum citrate (AlCit) was synthesized in our laboratory. The water used in the experiments was deionized and filtered through acetate film $(0.22 \mu \mathrm{m}) . \mathrm{NaCl}$ was produced by Beijing Shuanghuan Chemical Reagent Plant (China), $>99.5 \%$, GC grade.

Linked polymer solutions were prepared by mixing HPAM solution with $10 \% \mathrm{NaCl}$ solution, cross-linker aluminum citrate and deionized water at room temperature and the mixture was kept at $40{ }^{\circ} \mathrm{C}$ for 15 days for the crosslinking reaction to take place fully. The concentrations of HPAM and $\mathrm{NaCl}$ in LPS were $100 \mathrm{mg} / \mathrm{kg}$ and $500 \mathrm{mg} / \mathrm{kg}$, respectively. The mass ratio of HPAM to $\mathrm{Al}$ was 20:1.

The linked polymer solutions prepared from either unprocessed HPAM solution, HPAM solution oxygenated by adding oxygen or HPAM solution deoxygenated with nitrogen were allowed to degrade at $90{ }^{\circ} \mathrm{C}$. The oxygen content dissolved in LPS before degradation was measured with the colorimetric method.

\subsection{Micro-filtration}

The micro-filtration device is the same as that shown in literature (Dong et al, 2003). The micro-porous membrane used was a nucleopore membrane (supplied by China Institute of Atomic Energy) with an average pore diameter of $1.2 \mu \mathrm{m}$, a number of the pores per square centimeter of $5 \times 10^{6}$, and a thickness of $10 \mu \mathrm{m}$. The LPS solution was filtered under $0.1 \mathrm{MPa}$ at room temperature. The filtration time was noted 
when each $1 \mathrm{~mL}$ of LPS passing through the membrane, and the total LPS for micro-filtration was $20 \mathrm{~mL}$.

\subsection{Viscosity measurement}

The viscosity of HPAM solution was measured with a Ubbelode viscometer with a capillary diameter of $0.6 \mathrm{~mm}$. All the measurements were carried out at $(30 \pm 0.1){ }^{\circ} \mathrm{C}$.

\subsection{Dynamic light scattering experiment}

The average hydromechanical diameter $\left(D_{\mathrm{h}}\right)$ and size distribution of LPCs were measured by dynamic light scattering measurements with a Zetasizer-Nano-ZS (Malvern Instruments Ltd., UK). A $15 \mathrm{~mW}$ helium-neon laser (wave length in vacuum $\lambda=659 \mathrm{~nm}$ ) was used as the incident beam.

\section{Results and discussion}

\subsection{Oxidative stability of LPS}

The content of the dissolved oxygen in the deoxygenated, unprocessed and oxygen-added LPS samples was $0.3 \mathrm{mg} / \mathrm{kg}$, $4.0 \mathrm{mg} / \mathrm{kg}$ and $12.0 \mathrm{mg} / \mathrm{kg}$, respectively. LPS samples with different dissolved oxygen contents were allowed to degrade at $90{ }^{\circ} \mathrm{C}$ or $40{ }^{\circ} \mathrm{C}$ for micro-filtration and dynamic light scattering measurement.

\subsubsection{Plugging capability of LPS}

Fig. 1 shows the relationship of filtration time vs. degradation time for LPS with different oxygen contents at a degradation temperature of $90{ }^{\circ} \mathrm{C}$. It shows that with increasing degradation time, the time of $20 \mathrm{~mL}$ LPS (with different oxygen contents)passing through the nucleopore membrane was shortened. For $20 \mathrm{~mL}$ undegraded LPS, it took $176.2 \mathrm{~min}$ to pass through the nucleopore membrane. For the LPS containing $0.3 \mathrm{mg} / \mathrm{kg}$ oxygen, when it was degraded for $24 \mathrm{~h}$, the filtration time of which was $30 \mathrm{~min}$. When it was degraded for $48 \mathrm{~h}$, the filtration time was $2.1 \mathrm{~min}$. For the LPS with $4.0 \mathrm{mg} / \mathrm{kg}$ oxygen, when it was degraded for 24 $\mathrm{h}$, the filtration time was $5.2 \mathrm{~min}$. For the LPS with oxygen content of $12.0 \mathrm{mg} / \mathrm{kg}$, when it was degraded for $10 \mathrm{~h}$, the filtration time was $1.1 \mathrm{~min}$. In the both cases of $4.0 \mathrm{mg} / \mathrm{kg}$ and $12.0 \mathrm{mg} / \mathrm{kg}$ oxygen contents, LPS could not plug the membrane, indicating that the higher the dissolved oxygen content, the worse the oxidative stability of the LPS.

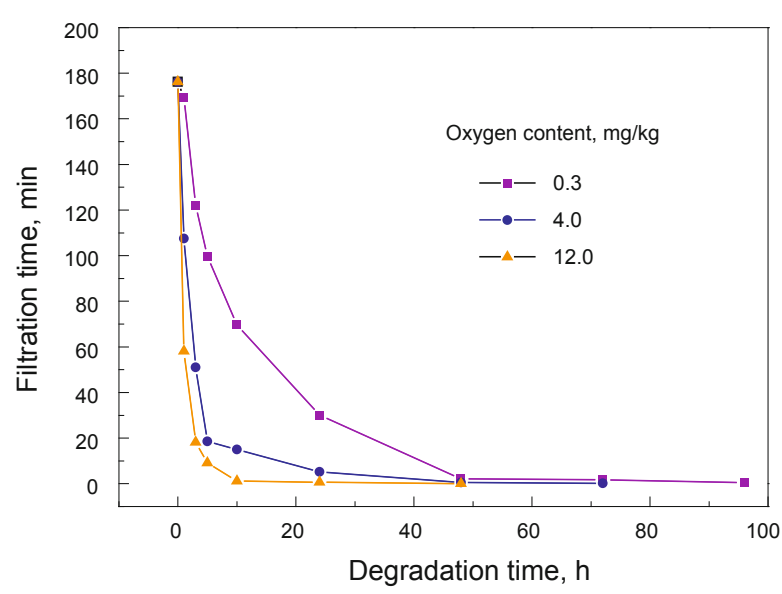

Fig. 1 Relationship of filtration time vs. degradation time for LPS with different oxygen contents (Degradation temperature: $90{ }^{\circ} \mathrm{C}$ )
Except for the oxygen content, the oxidative stability of the LPS was also affected by the degradation temperature (Fig. 2). The curves in Fig. 2 shows that after being degraded for $48 \mathrm{~h}$ at $40^{\circ} \mathrm{C}$ LPS still could plug the membrane, while after being degraded for $10 \mathrm{~h}$ at $90^{\circ} \mathrm{C}$ LPS could not plug the membrane, indicating that the LPS being degraded at lower temperature had higher oxidative stability.

Table 1 shows that the LPS, with $4.0 \mathrm{mg} / \mathrm{kg}$ and $12.0 \mathrm{mg} /$ $\mathrm{kg}$ oxygen contents, being degraded for $120 \mathrm{~h}$ at $40^{\circ} \mathrm{C}$, still could plug the membrane. The results further indicated that low degradation temperature can effectively improve the oxidative stability of LPS.

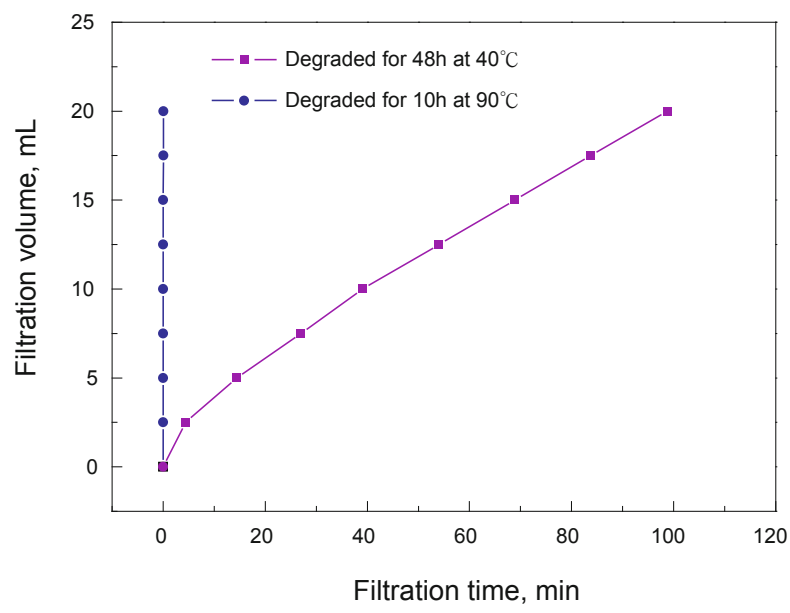

Fig. 2 Relationship of filtration volume vs. filtration time for LPS with an oxygen content of $12.0 \mathrm{mg} / \mathrm{kg}$

Table 1 Filtration time of $20 \mathrm{~mL}$ LPS with different oxygen contents after being degraded at $40{ }^{\circ} \mathrm{C}$

\begin{tabular}{cccc}
\hline & \multicolumn{3}{c}{ Filtration time (min) after being degraded } \\
Oxygen contents & \multicolumn{3}{c}{ for different times $(\mathrm{h})$} \\
\cline { 2 - 4 } $\mathrm{mg} / \mathrm{kg}$ & $0 \mathrm{~h}$ & $48 \mathrm{~h}$ & $120 \mathrm{~h}$ \\
\hline 4.0 & 176.2 & 159.1 & 166.0 \\
12.0 & 176.2 & 98.8 & 37.5 \\
\hline
\end{tabular}

Table 1 also shows that the filtration time of the LPS with $12.0 \mathrm{mg} / \mathrm{kg}$ oxygen was shortened significantly with the increase of degradation time, indicating that the LPS with higher dissolved oxygen content could degrade severely at 40 ${ }^{\circ} \mathrm{C}$. The degradation of the LPS led to the decrease in LPCs size hence lowered the ability to plug the membrane. The filtration time of the LPS with $4.0 \mathrm{mg} / \mathrm{kg}$ oxygen after being degraded for $120 \mathrm{~h}$ did not change greatly, indicating that the LPS with lower oxygen content is more oxidative stable at 40 ${ }^{\circ} \mathrm{C}$.

\subsubsection{Size of LPCs}

Fig. 3 shows the relationship of the average hydromechanical diameter $\left(D_{\mathrm{h}}\right)$ of LPC vs. degradation time for LPS with different dissolved oxygen contents after being degraded at $90{ }^{\circ} \mathrm{C}$. The average hydromechanical diameter $\left(D_{\mathrm{h}}\right)$ of the LPCs decreased with increasing degradation time. Before degradation, the $D_{\mathrm{h}}$ of the LPCs of all the LPS was 
$623 \mathrm{~nm}$. For the LPS with $0.3 \mathrm{mg} / \mathrm{kg}$ oxygen content, after being degraded for $48 \mathrm{~h}$, the $D_{\mathrm{h}}$ of the LPCs was $52 \mathrm{~nm}$. For the LPS with $4.0 \mathrm{mg} / \mathrm{kg}$ oxygen, after being degraded for 24 $\mathrm{h}$, the $D_{\mathrm{h}}$ of the LPCs was $55 \mathrm{~nm}$. For the LPS with $12.0 \mathrm{mg} /$ $\mathrm{kg}$ oxygen content, after being degraded for $10 \mathrm{~h}$ the $D_{\mathrm{h}}$ of the LPCs decreased below $50 \mathrm{~nm}$. The results indicate that degradation of the LPS was accelerated with the increase of the dissolved oxygen content. Combined with the results shown in Fig. 1, when the $D_{\mathrm{h}}$ of the LPCs decreased below 50 $\mathrm{nm}$, the LPS could not plug the membrane.

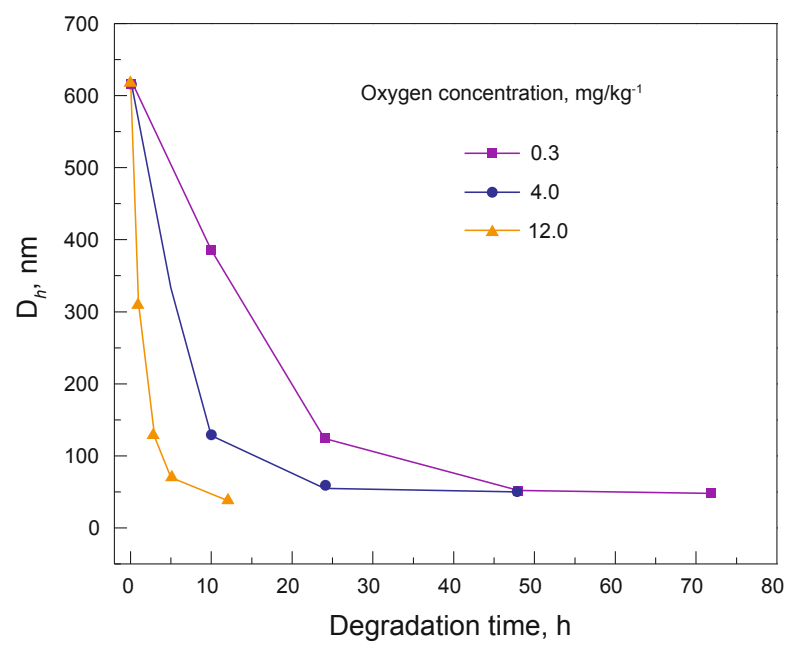

Fig. 3 Relationship of average hydromechanical diameter (Dh) of LPC vs. degradation time for LPS with different oxygen contents being degraded at $90{ }^{\circ} \mathrm{C}$

Fig. 4 shows that size distribution of the LPCs dispersed in the LPS with $0.3 \mathrm{mg} / \mathrm{kg}$ oxygen after being degraded. With the increase of the degradation time, the size of the LPCs decreases, and the distribution became narrow. At the same time, the number of small LPCs increases. The results further indicate that the decrease in LPCs size caused by degradation is one important reason why the LPS cannot plug the membrane.

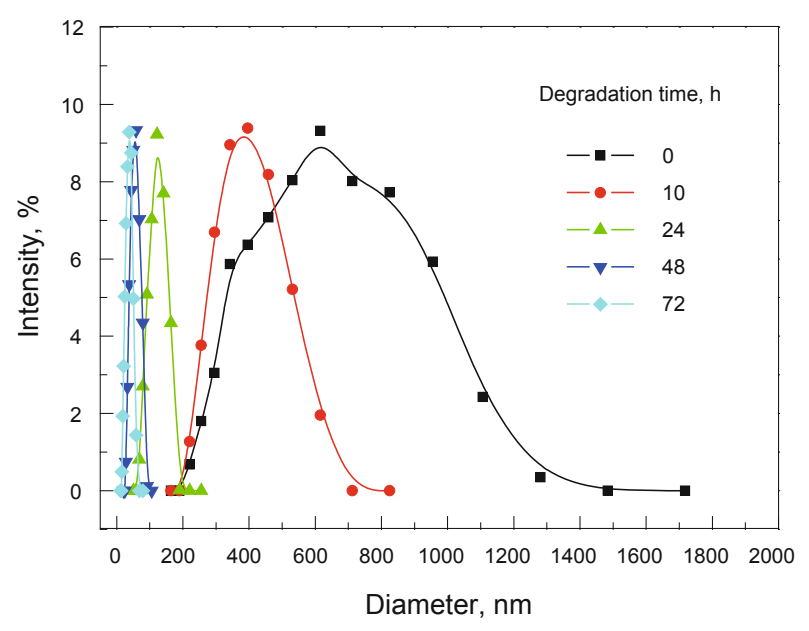

Fig. 4 Size distribution of LPCs of the LPS with $0.3 \mathrm{mg} / \mathrm{kg}$ oxygen content after being degraded for different times

\subsection{Oxidative stability of HPAM solution}

The dissolved oxygen contents of the deoxygenated, unprocessed, and oxygenated HPAM samples were 0.3, 4.0 and $12.0 \mathrm{mg} / \mathrm{kg}$, respectively. The HPAM solutions with concentrations of HPAM and $\mathrm{NaCl}$ in the solution being 100 and $500 \mathrm{mg} / \mathrm{kg}$, respectively, were degraded at $90{ }^{\circ} \mathrm{C}$ for investigating their oxidative stability by the viscosity method and dynamic light scattering experiment.

\subsubsection{Viscosity of HPAM solution}

Fig. 5 shows that the viscosity of the HPAM solutions decreases with increasing degradation time. Within the first $24 \mathrm{~h}$ of degradation, the viscosity decreased greatly. With further degradation, the viscosity decreased lightly, and the higher the dissolved oxygen content, the greater the viscosity changed.

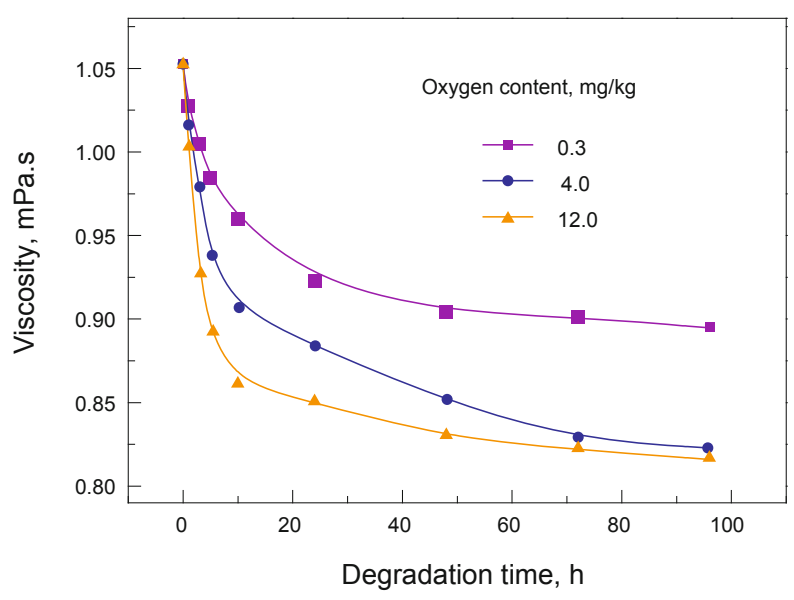

Fig. 5 Viscosity vs. degradation time for HPAM solutions being degraded at $90{ }^{\circ} \mathrm{C}$

\subsubsection{Size of HPAM coils}

Table 2 shows that the average hydromechanical diameter $\left(D_{\mathrm{h}}\right)$ of the HPAM coils decreased with increased degradation time at $90{ }^{\circ} \mathrm{C}$. The higher the dissolved oxygen content, the more rapid decrease in size of the HPAM coils. For the HPAM solution with $0.3 \mathrm{mg} / \mathrm{kg}$ oxygen, when it was degraded for $24 \mathrm{~h}$, the $D_{\mathrm{h}}$ of the HPAM coils decreased from $535 \mathrm{~nm}$ to $71 \mathrm{~nm}$. With further degradation time the decrease in size of the HPAM coils slowed down. For the HPAM solution with $12.0 \mathrm{mg} / \mathrm{kg}$ oxygen, when the degradation time was more than $10 \mathrm{~h}$, the size of the HPAM coils decreased slowly. The results of dynamic light scattering measurements agreed well with those of the viscosity measurements.

Table $2 D_{\mathrm{h}}$ of HPAM coils in the HPAM solution with different oxygen contents after being degraded for different times at $90{ }^{\circ} \mathrm{C}$

\begin{tabular}{c|cccc}
\hline $\begin{array}{c}\text { Degradation time of HAPM solution with } 0.3 \\
\text { mg/kg oxygen, } \mathrm{h}\end{array}$ & 0 & 10 & 24 & 48 \\
$D_{\mathrm{h}}$ of HAPM coils, nm & 535 & 225 & 71 & 45 \\
$\begin{array}{c}\text { Degradation time of HAPM solution with } \\
12.0 \mathrm{mg} / \mathrm{kg} \text { oxygen, h }\end{array}$ & 0 & 3 & 10 & 48 \\
$D_{\mathrm{h}}$ of HAPM coils, nm & 535 & 199 & 52 & 30 \\
\hline
\end{tabular}


The decrease in HPAM solution viscosity was related to the oxidative degradation of the HPAM molecules at high temperature. The results above indicate that the oxidative degradation of the HPAM molecules led to the HPAM molecules becoming smaller, and the solution viscosity declined accordingly. A high dissolved oxygen content accelerated the degradation of HPAM molecules and the extent of degradation increased. Consequently, at the same degradation time, the higher the dissolved oxygen content, the smaller the HPAM coils size, and the more rapid the decrease in HPAM solution viscosity.

\subsection{Results and discussion}

The oxidative degradation of HPAM is a free radical reaction (Eq.1-6) initiated by peroxide within the polymer (Zhan et al, 2004). When the dissolved oxygen content in solution is enough to produce oxygen free radicals, the degradation reaction will take place. As a result the HPAM molecule segments are broken, and the size of HPAM coils becomes small. Because the HPAM concentration in the LPS was low, the cross-linking degree of LPS was also low and only $8.96 \%$ of HPAM molecular segments were cross-linked (Dong et al, 2003). Since a large amount of HPAM molecular segments did not react with $\mathrm{Al}^{3+}$ of cross-linker, the oxidative stability of HPAM would affect the oxidative stability of LPS.

$$
\begin{aligned}
& \mathrm{POOH} \longrightarrow \mathrm{PO} \cdot+\cdot \mathrm{OH} \\
& \mathrm{PH}+\cdot \mathrm{OH} \longrightarrow \mathrm{P} \cdot+\mathrm{H}_{2} \mathrm{O} \\
& \mathrm{PO} \cdot+\mathrm{O}_{2} \longrightarrow \mathrm{POO} \cdot \\
& \mathrm{POO} \cdot+\mathrm{PH} \longrightarrow \mathrm{POOH}+\mathrm{P} .
\end{aligned}
$$

Where, "P" represents the alkyl chain of HPAM molecules.<smiles>[R]C(=O)C(CC(C([R])=O)C([R])=O)CC(O)(CC)C([R])=O</smiles>

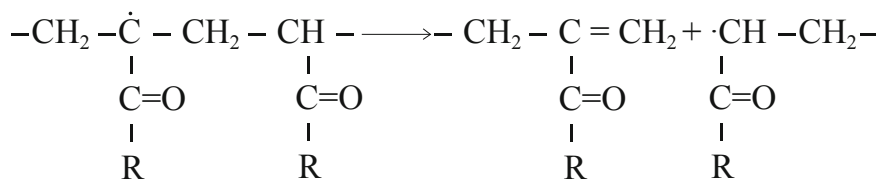

When LPS degraded at high temperature, firstly the HPAM molecular segments were broken, and the size of LPCs became small. At the same time, the structure of the HPAM molecules changed after degradation. The cross-link between the HPAM molecules and cross-linker was destroyed, and the number of the LPCs decreased. Consequently, LPS lost the ability of plugging the membrane.

\section{Conclusions}

(1) At the same temperature, the degree of the oxidative degradation of LPS increased and the oxidative degradation accelerated with the increase of the dissolved oxygen content. Consequently, the size of LPCs became small, and the plugging capability of the LPS decreased.

(2) At a fixed dissolved oxygen content, with increasing degradation temperature, almost the same results were observed, namely, the degree of oxidative degradation increased, the oxidative degradation accelerated and the plugging capacity decreased, with decreased oxidative stability of LPS.

(3) At $90^{\circ} \mathrm{C}$, with high oxygen content, LPS lost its plugging ability after being degraded for a period of time. But at $40{ }^{\circ} \mathrm{C}$, LPS with low dissolved oxygen content could be stable for a long time.

(4) The decreased plugging capacity of LPS after oxidative degradation is mainly caused by the decreased size and number of LPCs due to the breaking of HPAM molecule segments and the structural change of HPAM molecules.

\section{References}

Dong Z X, Li M Y, Wu Z L, et al. Deformation of linked polymer coils. Chinese Journal of Chemical Engineering. 2003. 11(6): 686-690

Li M Y, Wang A H, Yu X R, et al. The flowing diversion mechanism of linked polymer solution. Acta Petrolei Sinica (Petroleum Processing Section). 2007. 23(6): 31-35 (in Chinese)

Li M Y, Zheng X Y, Lin M Q, et al. Experiment in situ taking linked polymer solution (LPS) as in-depth profile control agent. Acta Petrolei Sinica (Petroleum Processing Section). 2002. 23(6): $72-76$ (in Chinese)

Lin M Q, Xin J, Li M Y, et al. Study on the shear-stability of low concentration HPAM/AlCit crosslinked polymer system. Acta Polymerica Sinica. 2008a (1): 8-12 (in Chinese)

Lin M Q, Wang Z J, Li M Y, et al. Thermal stability of linked polymer solution. Acta Petrolei Sinica (Petroleum Processing Section). 2008b. 24(1): 112-116 (in Chinese)

Lin M Q, Dong Z X, Li M Y, et al. (27) Al NMR studies on HPAM/ AlCit crosslinking system with low concentration polymer. Chemical Journal of Chinese Universities. 2007. 8(8): 1573-1576 (in Chinese)

Luo X H, Lin M Q, Dong Z X, et al. Study on influencing factors for plugging performance of LPS. Membrane Science and Technology. 2006. 26(1): 88-91 (in Chinese)

Luo X B, Pu W F, Zhao J Z, et al. Experimental study of the dynamic flowing gelling time of crosslinked polymer solution and its transfer process in porous medium. Journal of Southwest Petroleum Institute. 2005. 27(5): $72-74$ (in Chinese)

Shi G, Pu S Z, Li M Y, et al. Flowing and plugging behavior of linked polymer solutions in porous media. Journal of Chemical Industry and Engineering (China). 2008. 59(5): 1114-1121 (in Chinese)

Sun $\mathrm{A} \mathrm{J}, \mathrm{Wu} \mathrm{Z} \mathrm{L,} \mathrm{Lin} \mathrm{M} \mathrm{Q,} \mathrm{et} \mathrm{al.} \mathrm{Viscosity} \mathrm{change} \mathrm{of} \mathrm{partially}$ hydrolyzed polyacrylamide-Aluminum citrate system crosslinking reaction. Journal of China University of Petroleum (Edition of Natural Science). 2003.27(5): 96-98, 102 (in Chinese)

Sun A J, Lin M Q, Li M Y, et al. Rheological properties of linked polymer solution made of low concentration partially hydrolyzed polyacrylamide and aluminum citrate. Journal of China University 
of Petroleum (Edition of Natural Science). 2004. 28(5): 65-69 (in Chinese)

Sun Z B, Zheng Y X, Li M Y, et al. Study on mechanism of plugging porous media of linked polymer solution. Polymer Materials Science \& Engineering. 2005a. 21(2): 225-228, 232 (in Chinese)

Sun Z B, Zheng Y X, Li M Y, et al. Breakthrough performance of the linked polymer solution. Journal of Chemical Engineering of Chinese Universities. 2005b. 9(5): 608-612 (in Chinese)
Zhan Y L, Guo S H, Yan G X. Study on degradation of partially hydrolyzed polyacrylamide. Polymer Bulletin. 2004(2): 70-74 (in Chinese)

Zhu B, Wang J and Xin M R. Influence of HPAM relative molecular weight and electrolyte on LPS plugging capacity. Applied Chemistry Industry. 2006. 35(7): 514-516 (in Chinese)

(Edited by Zhu Xiuqin) 